\title{
Prevalence of obstetric anal sphincter injury following vaginal delivery in primiparous women: a retrospective analysis
}

\author{
Sonia PK Kwok, Osanna YK Wan, Rachel YK Cheung, LL Lee, Jacqueline PW Chung, \\ Symphorosa SC Chan *
}

\section{A B S T R A C T}

Introduction: Obstetric anal sphincter injuries (OASIS) may be underdetected in primiparous women. This study evaluated the prevalence of OASIS in primiparous women after normal vaginal delivery or instrumental delivery using endoanal ultrasound (US) during postnatal follow-up.

Methods: This study retrospectively analysed endoanal US data collected during postnatal follow-up (6-12 months after vaginal delivery) at a tertiary hospital in Hong Kong. Offline analysis to determine the prevalence of OASIS was performed by two researchers who were blinded to the clinical diagnosis. Symptoms of faecal and flatal incontinence were assessed with the Pelvic Floor Distress Inventory.

Results: Of 542 women included in the study, 205 had normal vaginal delivery and 337 had instrumental delivery. The prevalence of OASIS detected by endoanal US was 7.8\% (95\% confidence interval $[\mathrm{CI}]=4.1 \%-11.5 \%)$ in the normal vaginal delivery group and $5.6 \%$ (95\% $\mathrm{CI}=3.1 \%-8.1 \%)$ in of women with OASIS on endoanal US did not show clinical signs of OASIS. Birth weight was significantly higher in the OASIS group ( $\mathrm{P}=0.012)$. At 6 to 12 months after delivery, $5.5 \%$ of women reported faecal incontinence and $17.9 \%$ reported flatal incontinence, but OASIS was not associated with these symptoms.

Conclusions: Additional training for midwives and doctors may improve OASIS detection.

\section{Hong Kong Med J 2019;25:271-8}

https://doi.org/10.12809/hkmj197842

SPK Kwok, MB, ChB, MRCOG

OYK Wan, FHKAM (Obstetrics and Gynaecology), FHKCOG

RYK Cheung, FHKAM (Obstetrics and Gynaecology), FHKCOG

LL Lee, MSc

JPW Chung, FHKAM (Obstetrics and Gynaecology), FHKCOG

SSC Chan *, MD, FRCOG

Department of Obstetrics and Gynaecology, The Chinese University of Hong Kong, Shatin, Hong Kong

the instrumental delivery group. Overall, 82.9\% * Corresponding author: symphorosa@cuhk.edu.hk

New knowledge added by this study

- The prevalence of obstetric anal sphincter injury in primiparous women was $7.8 \%$ in the normal vaginal delivery group and $5.6 \%$ in the instrumental delivery group.

- Most obstetric anal sphincter injuries, as determined by endoanal ultrasound, were not detected clinically. At 6 to 12 months after delivery, obstetric anal sphincter injuries were not associated with symptoms of faecal or flatal incontinence, but a longer-term study is needed to confirm these findings.

Implications for clinical practice or policy

- Obstetric anal sphincter injuries occur at similar rates during normal vaginal delivery and instrumental delivery. Detailed vaginal and rectal examinations are recommended after both types of deliveries.

- Additional training for midwives and doctors may improve the detection of obstetric anal sphincter injury.

\section{Introduction}

Obstetric anal sphincter injuries (OASIS) is a serious complication of vaginal delivery that is associated with an increased risk of anal incontinence (complaint of involuntary loss of faeces or flatus). The incidence of OASIS is reportedly much lower in Hong Kong $(0.32 \%)$ than in other countries, such as the United Kingdom, Norway, and Sweden $(2.9 \%-4.2 \%) .^{2-5}$ This could be affected by a number of factors. First, delivery practices in Hong Kong are quite different from elsewhere in the world, such that they include the use of a hands-on approach to protect the perineum and liberal use of episiotomy. ${ }^{6}$ The episiotomy rates are reportedly high in Hong Kong: $83.7 \%$ for primiparous women and $54.8 \%$ for multiparous women. ${ }^{5}$ Moreover, in Hong Kong, a left mediolateral episiotomy is used, whereas midline episiotomy or right mediolateral episiotomy are used in many other parts of the world. ${ }^{7}$ Second, there may be ethnic differences in pelvic floor biometry. In particular, Chinese women have a smaller hiatal dimension and reduced pelvic organ mobility. ${ }^{8}$ It is 


\section{初產婦於陰道分娩後患有肛門括約肌損傷的 患病率：回顧性研究 \\ 郭沛琦、温綺琪、張優嘉、李麗萊、鍾佩樺、陳丞智}

引言：初產婦於陰道分娩後, 臨床檢查有可能未能完全檢測到肛門括 約肌的損傷。本研究透過為初產婦於陰道分娩後, 在產後覆診期間, 使用肛門超聲波 探測肛門括約肌的損傷, 從而得出肛門括約肌損傷的 患病率。

方法：本研究回顧性分析在香港一所大學醫院於產後覆診（陰道分婏 後6-12個月）期間收集的肛門超聲波數據。兩名對臨床診斷不知情的 研究人員各自分析超聲波數據, 以得出肛門括約肌損傷的患病率。使 用經驗證的盆底功能障礙簡表（PFDI）對粪便失禁症狀進行評估。

結果：研究包括542名女性, 其中205名屬於陰道正常分婏, 337名屬 於儀器助產陰道分娩。在正常陰道分娩的女性中, 透過使用肛門超聲 波檢測到的肛門括約肌損傷的患病率為7.8\%（95\%置信區間：4.1\%$11.5 \%$ ）, 儀器助產陰道分娩的女性的患病率為 5.6\%（95\%置信區 間：3.1\%-8.1\%）。82.9\%用超聲波測出有肛門括約肌受損的個案並未 能於臨床檢查中診斷。肛門括約肌受損者的嬰兒出生體重顯著較沒有 受損的重（ $\mathrm{P}=0.012 ） 。$ 分娩後6至 12 個月, $5.5 \%$ 女性出現大便失禁 的症狀, $17.9 \%$ 女性出現屁失禁的症狀, 但這些症狀與肛門括約肌損 傷並無關聯。

結論：加強培訓助產士和醫生有可能改善臨床檢查時對肛門括約肌損 傷的診斷。
Understanding the prevalence and detection rates of OASIS can help inform training policies for midwives and doctors on the awareness and detection of OASIS.

\section{Methods}

\section{Patients and study design}

This was a retrospective analysis of archived US volumes from two previously published studies that were performed at a tertiary university hospital in Hong Kong. The initial study recruited 442 nulliparous women in the first trimester, during the period from August 2009 to September $2010 .{ }^{12,13}$ The second study recruited 292 primiparous women at 1 to 3 days after instrumental delivery, during the period from September 2011 to May 2012. None of the women in either study reported symptoms of pelvic floor disorders, including faecal incontinence to solid or loose stool, before pregnancy. ${ }^{14}$ Details of deliveries, including any occurrence of perineal tearing, were recorded after each delivery. Ethics approval was obtained from The Joint Chinese University of Hong Kong-New Territories East Cluster Clinical Research Ethics Committee (Ref CRE-2013.332). The STROBE (Strengthening the Reporting of Observational Studies in Epidemiology) guidelines were followed in the preparation of this report. ${ }^{15}$

\section{Delivery and immediate assessment}

unclear how these differences in practice and pelvic floor biometry influence the incidence of OASIS. Importantly, it is also possible that the reduced incidence of OASIS in Hong Kong is a result of underdetection. In a recent local prospective observational study, women were assessed by a single experienced clinician via rectal examination after either normal or instrumental vaginal delivery; the results of that study showed that the incidence of OASIS in primiparous Asian women in Hong Kong was $10 \%,{ }^{6}$ which suggests that the OASIS rate might be higher than previously published. Obstetric anal sphincter injuries that are identified after an extended interval (such as during postnatal follow-up) is regarded as occult OASIS. There is limited information in the literature regarding occult OASIS; thus far, studies have been conducted in the United Kingdom and Australia. ${ }^{9,10}$

The use of endoanal ultrasound (US) may facilitate identification of OASIS. ${ }^{11}$ Endoanal US comprises a non-invasive assessment modality and is regarded as the gold standard in studies of anal sphincter injury. ${ }^{9,11}$ Moreover, all cases of clinically identified OASIS can also be identified on endoanal US. ${ }^{9}$ The aim of this study was to determine the prevalence of OASIS in primiparous women after normal vaginal delivery or instrumental delivery using endoanal US during postnatal follow-up.
Generally, each woman underwent perineal examination by the attending midwife or doctor who conducted the delivery, immediately after vaginal delivery. This information was immediately recorded in the medical record. Third- or fourth-degree tears were assessed and repaired by a trained obstetrician. The anorectal mucosa was repaired by continuous or interrupted sutures with 3-O Vicryl. Internal anal sphincter tears were repaired separately by interrupted end-to-end sutures with 2-O Vicryl. External anal sphincter (EAS) tears were repaired by overlapping or end-to-end sutures with 2-O Vicryl. Perineal muscles and the vagina were repaired with 2-O Vicryl. The diagnosis and operative record of each woman were immediately entered into the electronic medical record. The degree of perineal tear was defined using Sultan's classification of perineal trauma. ${ }^{16}$

\section{Follow-up assessment}

During postnatal follow-up (6-12 months after delivery), the urinary, bowel, and prolapse symptoms of each woman, as well as their quality of life, were assessed using the Chinese Pelvic Floor Distress Inventory (PFDI) and Pelvic Floor Impact Questionnaire (PFIQ). ${ }^{17}$ Assessment of the anal sphincter was performed with endoanal US using a 
10-MHz 360-degree rotating probe (Focus 400, BK Medical; Gentofte, Denmark) with the woman in the lithotomy position. Automatic image acquisition was performed with two volumes stored for each woman.

\section{Blinded offline analysis of endoanal ultrasound}

Offline analysis of the endoanal US volumes was performed in 2018 by two experienced obstetricians (OYKW, SSCC) who were blinded to the clinical diagnosis and questionnaire information. An anal sphincter defect was defined as a discontinuity of $>30$ degrees in endosonographic images of the internal (hypoechoic ring) and/or external (mixed echogenic ring) sphincters. ${ }^{18} \mathrm{~A}$ partial-thickness EAS injury was defined as a defect of $<50 \%$ thickness of the EAS, whereas a defect of $>50 \%$ of the EAS was regarded as a full-thickness injury. We considered any EAS and/or internal anal sphincter injury to be OASIS. This follows the clinical classification of OASIS by Sultan. ${ }^{16}$ Each researcher reviewed all endoanal US volumes independently. Any discrepancies were resolved by consensus review of the relevant US volumes.

\section{Definitions of incontinence}

The PFDI and PFIQ are comprehensive validated instruments which assess the symptoms and impact of pelvic floor disorders. ${ }^{17}$ In this study, faecal incontinence was defined as an affirmative response to either item 38 ("Do you usually lose stool beyond your control if your stool is well formed?") or item 39 ("Do you lose stool beyond your control if your stool is loose or liquid?") of the PFDI. Flatal incontinence was defined as an affirmative response to item 40 ("Do you usually lose gas from the rectum beyond your control?") of the PFDI.

\section{Statistical analysis}

Data were analysed by SPSS (Window version 22.0; IBM Corp, Armonk [NY], United States). Descriptive analyses were used to study the prevalence of OASIS on endoanal US. Means were compared between groups using the independent-samples $t$ test. Comparisons of frequencies were made using the Chi squared test or Fisher's exact test, where appropriate. Univariate analysis was performed to evaluate the influence of potential risk factors on OASIS. Differences with $\mathrm{P}<0.05$ were considered to be statistically significant. Power calculations were not performed with regard to this specific research question, as this study comprised a subanalysis of two prior projects, as described earlier in this paper.

\section{Results}

\section{Patient characteristics}

A total of 544 women who had vaginal delivery were enrolled in this study; 207 had normal vaginal delivery and 337 had instrumental delivery (285 vacuum extraction, 52 forceps). Ultrasound images were suboptimal for two women who had normal vaginal delivery; these women were excluded from the analysis.

The demographic data and delivery information are shown in Table 1. Left mediolateral episiotomy was performed in 187 (91.2\%) women in the normal vaginal delivery and 336 (99.7\%) women in the instrumental delivery group. The duration of active second stage was longer in the instrumental delivery group than in the normal vaginal delivery group $(62.7 \pm 40.9 \mathrm{~min}$ vs $27.9 \pm 22.4 \mathrm{~min}, \mathrm{P}<0.005)$, as a prolonged second stage was the most common indication for instrumental delivery in this cohort (48.4\%). More women had epidural analgesia in the instrumental delivery group than in the normal vaginal delivery group $(15.7 \%$ vs $8.8 \%, \mathrm{P}=0.028)$.

TABLE I. Baseline characteristics of 542 women with vaginal delivery*

\begin{tabular}{|c|c|c|c|c|}
\hline & All $(n=542)$ & NVD (n=205) & $\begin{array}{l}\text { Instrumental } \\
\quad(n=337)\end{array}$ & $\mathrm{P}$ value \\
\hline Maternal age at delivery (years) & $30.8 \pm 3.7$ & $30.9 \pm 3.4$ & $30.8 \pm 3.9$ & 0.649 \\
\hline Maternal BMI at follow-up of this study $\left(\mathrm{kg} / \mathrm{m}^{2}\right)$ & $22.7 \pm 3.0$ & $22.8 \pm 3.1$ & $22.7 \pm 3.0$ & 0.897 \\
\hline Epidural analgesia & $71(13.1 \%)$ & $18(8.8 \%)$ & $53(15.7 \%)$ & 0.028 \\
\hline Gestational age at delivery (weeks) & $39.4 \pm 1.2$ & $39.3 \pm 1.2$ & $39.5 \pm 1.3$ & 0.079 \\
\hline Birth weight (kg) & $3.14 \pm 0.39$ & $3.12 \pm 0.39$ & $3.15 \pm 0.40$ & 0.428 \\
\hline Duration of active second stage of labour (min) & $49.6 \pm 38.9$ & $27.9 \pm 22.4$ & $62.7 \pm 40.9$ & $<0.005$ \\
\hline Episiotomy & $523(96.5 \%)$ & $187(91.2 \%)$ & $336(99.7 \%)$ & $<0.005$ \\
\hline Clinical 3rd or 4th degree perineal tear & $6(1.1 \%)$ & 0 & $6(1.8 \%)$ & 0.134 \\
\hline
\end{tabular}

Abbreviations: $\mathrm{BMI}=$ body mass index; $\mathrm{NVD}=$ normal vaginal delivery

* Data are shown as mean \pm standard deviation or No. (\%), unless otherwise specified

+ Comparison between NVD and instrumental delivery groups 
There was no significant difference between the normal vaginal delivery and instrumental delivery groups regarding the timing of endoanal US assessment $(\mathrm{P}=0.22)$.

\section{Endoanal ultrasound findings and relationship of obstetric anal sphincter injuries with delivery factors}

The Figure shows endoanal US images of intact anal sphincters, as well as sphincters with different degrees of OASIS. There were discrepancies or uncertainties in the endoanal US analysis of 16 women with respect to the diagnosis of OASIS. The two researchers determined the diagnoses of these women by consensus review; six were diagnosed with OASIS and 10 were regarded as normal.
The prevalence of clinically detected OASIS was $0 \%$ in the normal vaginal delivery group and $1.8 \%(n=6)$ in the instrumental delivery group. Table 2 shows that the prevalence of OASIS detected by endoanal US was $7.8 \%(n=16 ; 95 \%$ confidence interval $[\mathrm{CI}]=4.1 \%-11.5 \%)$ in the normal vaginal delivery group and $5.6 \%(\mathrm{n}=19 ; 95 \% \mathrm{CI}=3.1 \%-8.1 \%)$ in the instrumental delivery group $(\mathrm{P}=0.415)$. Twentynine $(82.9 \%)$ women had OASIS, as detected by endoanal US, that was not diagnosed during clinical assessment immediately after delivery. Therefore, the occult OASIS rate was $7.8 \%$ (95\% CI=4.1\%-11.5\%) in the normal vaginal delivery group and 3.8\% (95\% $\mathrm{CI}=1.8 \%-5.8 \%)$ in the instrumental delivery group. In addition, $63.6 \%(n=21)$ of occult EAS injuries comprised partial-thickness EAS injuries, whereas $36.4 \%(n=12)$ comprised full-thickness EAS injuries.
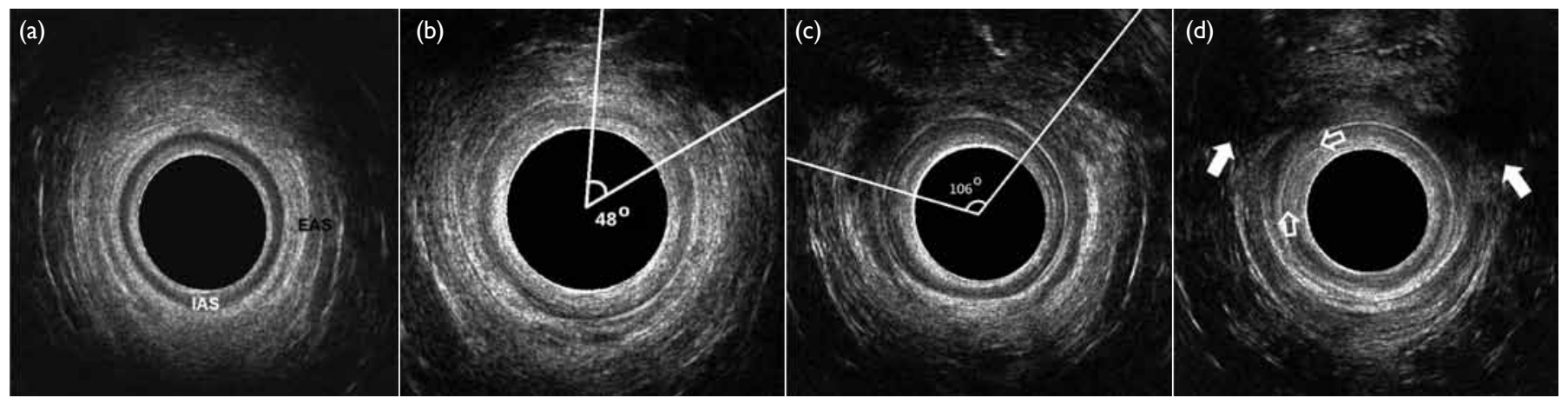

FIG. (a) Endoanal ultrasound of a 34-year-old woman after normal vaginal delivery. She was asymptomatic of anal incontinence. There was a complete hypoechoic ring (IAS) and mixed echogenic ring (EAS), signifying intact IAS and EAS with no OASIS. (b) Endoanal ultrasound of a 34-year-old woman after vacuum extraction. She was asymptomatic of anal incontinence. There was a hypoechoic defect of 48 degrees in the EAS involving less than half of the thickness of the EAS, indicating an occult partial-thickness EAS injury. The IAS was intact. (c) Endoanal ultrasound of a 29-year-old woman after vacuum extraction. She was diagnosed with a third degree (grade 3a) tear with repair done after delivery.A hypoechoic area in the EAS was present from 9 to 2 o'clock region (I06 degrees) spanning the full thickness of the EAS; while the IAS was intact. She did not have symptoms of anal incontinence. (d) Endoanal ultrasound of a 30-year-old woman after normal vaginal delivery with occult anal sphincter injury. There was a hypoechogenic area at 10 to 2 o'clock region (between solid arrows) involving full thickness of the EAS and a discontinuity in the hypoechoic ring which was the IAS at 9 to II o'clock (between arrow outlines), signifying both EAS and IAS injury. She was asymptomatic of anal incontinence Abbreviations: $\mathrm{EAS}=$ external anal sphincter; IAS = internal anal sphincter; OASIS = obstetric anal sphincter injury

TABLE 2. Rate of OASIS detected by endoanal US*

\begin{tabular}{|c|c|c|c|c|c|c|}
\hline & Total $(n=542)$ & NVD (n=205) & $\begin{array}{l}\text { Instrumental } \\
\quad(n=337)\end{array}$ & VE $(n=285)$ & $\operatorname{Fr}(n=52)$ & $P$ valuet \\
\hline EAS injury & $33(6.1 \%)$ & $14(6.8 \%)$ & $19(5.6 \%)$ & $16(5.6 \%)$ & $3(5.8 \%)$ & 1.0 \\
\hline Partial-thickness EAS injury & $21(3.9 \%)$ & $8(3.9 \%)$ & $13(3.9 \%)$ & $11(3.9 \%)$ & $2(3.8 \%)$ & \\
\hline Full-thickness EAS injury & $12(2.2 \%)$ & $6(2.9 \%)$ & $6(1.8 \%)$ & $5(1.8 \%)$ & $1(1.9 \%)$ & \\
\hline IAS injury & $8(1.5 \%)$ & $7(3.4 \%)$ & $1(0.3 \%)$ & $1(0.4 \%)$ & 0 & - \\
\hline Isolated IAS & $2(0.4 \%)$ & $2(1.0 \%)$ & 0 & 0 & 0 & \\
\hline Both EAS and IAS injury & $6(1.1 \%)$ & $5(2.4 \%)$ & $1(0.3 \%)$ & $1(0.4 \%)$ & 0 & \\
\hline OASIS & 35 (6.5\%) & 16 (7.8\%) & 19 (5.6\%) & $16(5.6 \%)$ & $3(5.8 \%)$ & 1.0 \\
\hline
\end{tabular}

Abbreviations: EAS = external anal sphincter; $\mathrm{Fr}=$ forceps delivery; IAS = internal anal sphincter; NVD = normal vaginal delivery; OASIS = obstetric anal sphincter injury; US = ultrasound; VE = vacuum extraction

* Data are shown as No. (\%), unless otherwise specified

† Comparison between VE and Fr groups 
When women with OASIS were compared to those without OASIS, increased birth weight was the only delivery factor associated with an increased risk of OASIS (odds ratio $[\mathrm{OR}]=3.1,95 \% \mathrm{CI}=1.3 \%-7.6 \%$, $\mathrm{P}=0.012$ ) [Table 3].

\section{Relationships of faecal and flatal incontinence symptoms with obstetric anal sphincter injuries}

Overall, nine (1.7\%) and 29 (5.4\%) women reported faecal incontinence to solid and loose stool, whereas 97 (17.9\%) women reported flatal incontinence (Table 4). All affected women reported mild symptoms. Among the women with OASIS, only one $(2.9 \%)$ with a repaired third degree (3a) tear reported symptoms of both (faecal incontinence to loose stool and flatal incontinence). Three women (10.3\%) who had occult injury reported flatal incontinence. There were no associations between the presence of OASIS and faecal incontinence $(\mathrm{P}=0.71)$ or between the presence of OASIS and flatal incontinence $(\mathrm{P}=0.37)$.

\section{Discussion}

Primiparity has been associated with increased risks of OASIS (ORs of 2.39 and 8.34) in large retrospective studies. ${ }^{19,20}$ In the present study, which included large number of primiparous women, the findings on endoanal US were compared with women's reported symptoms of faecal and flatal incontinence. Importantly, there were no associations between faecal or flatal incontinence and the presence of OASIS.

After assessment by endoanal US, the prevalence of OASIS in the normal vaginal delivery group increased from $0 \%$ to $7.8 \%$ and that in the instrumental delivery group increased from 1.8\% to $5.6 \%$. Overall, $82.9 \%$ of women with OASIS detected by endoanal US had not been diagnosed with OASIS during clinical assessment immediately after delivery. This finding is consistent with the results of the study by Andrews et al. ${ }^{9}$ In that study, the prevalence of OASIS markedly increased from $11 \%$ to $24.5 \%$ when women were re-examined by an experienced research fellow; $87 \%$ of OASIS diagnoses were missed by midwives and $28 \%$ were missed by junior doctors. ${ }^{9}$ In our study, normal vaginal deliveries were primarily attended by midwives, whereas instrumental deliveries were performed by residents. The higher rate of occult OASIS in the normal vaginal delivery group suggests that midwives currently receive inadequate training for clinical identification of OASIS. Thus, to improve the detection of OASIS, midwives and doctors should be trained to recognise OASIS by performing a standardised vaginal and rectal examination after delivery.

Compared with previous studies, the rate of OASIS determined by endoanal US in our study

TABLE 3. Correlation between OASIS and delivery factors*

\begin{tabular}{lccc}
\hline & OASIS (n=35) & No OASIS (n=507) & P value \\
\hline Maternal age at delivery (years) & $31.3 \pm 3.3$ & $30.8 \pm 3.7$ & 0.412 \\
\hline Maternal BMI at this study $\left(\mathrm{kg} / \mathrm{m}^{2}\right)$ & $22.5 \pm 2.6$ & $22.8 \pm 3.1$ & 0.647 \\
Epidural analgesia & $4(11.4 \%)$ & $67(13.2 \%)$ & 0.965 \\
Gestational age at delivery (weeks) & $39.7 \pm 1.3$ & $39.4 \pm 1.2$ & 0.240 \\
Birth weight (kg) & $3.30 \pm 0.40$ & $3.12 \pm 0.39$ & 0.012 \\
Duration of active second stage of labour (min) & $43.6 \pm 37.6$ & $50.0 \pm 39.0$ & 0.348 \\
Instrumental delivery & $19(54.3 \%)$ & $318(62.7 \%)$ & 0.415 \\
\hline Episiotomy & $33(94.3 \%)$ & $490(96.6 \%)$ & 0.795 \\
\hline
\end{tabular}

Abbreviations: $\mathrm{BMI}=$ body mass index; OASIS = obstetric anal sphincter injury

* Data are shown as mean \pm standard deviation or No. (\%), unless otherwise specified

TABLE 4. Incidences of faecal and flatal incontinence symptoms and their associations with OASIS*

\begin{tabular}{cccccc}
\hline & No & Yes & No OASIS (n=507) & $\begin{array}{c}\text { Repaired clinical } \\
\text { injury (n=6) }\end{array}$ & $\begin{array}{c}\text { Occult injury } \\
(\mathbf{n}=\mathbf{2 9})\end{array}$ \\
\hline Faecal incontinence & $512(94.5 \%)$ & $30(5.5 \%)$ & $29(5.7 \%)$ & $1(16.7 \%)$ & 0 \\
Solid stool & $533(98.3 \%)$ & $9(1.7 \%)$ & $9(1.8 \%)$ & 0 & 0 \\
Loose stool & $513(94.6 \%)$ & $29(5.4 \%)$ & $28(5.5 \%)$ & $1(16.7 \%)$ & 0 \\
Flatal incontinence & $445(82.1 \%)$ & $97(17.9 \%)$ & $93(18.3 \%)$ & $1(16.7 \%)$ & $3(10.3 \%)$ \\
\hline
\end{tabular}

Abbreviation: OASIS = obstetric anal sphincter injury

* Data are shown as No. (\%) 
(6.5\%) was lower than the rate of $10 \%$ determined by a single examiner in a prospective observational study conducted in the same unit. ${ }^{6}$ This could be a result of the small sample size (70 subjects) in the prior study. Furthermore, most patients with OASIS $(5 / 7)$ in that study were reported to have small $3 a$ tears. There were no $3 \mathrm{c}$ or fourth-degree tears in that study. Following the same delivery practices, clinically detected small $3 a$ tears may therefore appear normal in endoanal US. Furthermore, these tears might not result in long-term consequences. ${ }^{6,21}$

The finding of an overall lower OASIS rate in Hong Kong, compared with that in Asian women who deliver in Caucasian countries, is not new. Asian women who deliver in locations with more restrictive policies regarding episiotomy have shown higher rates of OASIS. ${ }^{22-24}$ In a study conducted in the United States, OASIS was found significantly more frequently in Asian women than in women of other ethnicities. ${ }^{23}$ In Australia, nulliparous women born in South Asia and South-East Asia were 2.6fold and 2.1-fold more likely to exhibit OASIS than women born in Australia or New Zealand women. ${ }^{24}$ It is uncertain whether the increased rate of episiotomy might protect against OASIS in Asian women and contribute to the relative reduction in the rate of OASIS in Hong Kong. Thus, our unit is currently conducting a randomised controlled trial to compare restrictive and routine episiotomy. In addition to episiotomy, the delivery technique and hands-on approach might contribute to the relative reduction in the rate of OASIS. All deliveries in our study were conducted with women in a lithotomy position, with their feet on footplates or in stirrups. All midwives and doctors conducting the deliveries used hands-on techniques to protect the perineum in each woman. Either firm pressure or pressure with squeezing of the perineum, also known as the modified Ritgen manoeuvre, was used. ${ }^{6}$ Warm compresses were not commonly used by midwives and doctors in our study.

The OASIS rate in the normal vaginal delivery group was higher than that in the the instrumental delivery group, but this difference was not statistically significant. The majority of deliveries by women in the instrumental delivery group were performed using vacuum extraction. The rate of OASIS in these women could be similar to that of women in the normal vaginal delivery group. The OASIS rates were similar in women who delivered with the aid of vacuum extraction or with forceps, whereas previous studies showed that forceps delivery was associated with an increased risk of OASIS. 19,20,25 The small number of forceps deliveries in this study might have led to insufficient statistical power to detect a difference between the two types of instrumental deliveries. Furthermore, the use of forceps was primarily restricted to patients who were low risk, and mostly comprised outlet/lowcavity forceps deliveries. Previous studies reported that macrosomia, higher birth weight $(\mathrm{OR}=1.14,95 \%$ $\mathrm{CI}=1.0-1.3, \mathrm{P}=0.039$ ), and shorter perineal length were risk factors for OASIS. ${ }^{6,19,20}$ The present study had similar findings, in that higher birth weight was a risk factor for OASIS (OR=3.1, 95\% CI=1.3-7.6, $\mathrm{P}=0.012$ ). However, perineal length was not assessed, which is an important limitation of this study.

Flatal incontinence was present in $17.9 \%$ of women after delivery, which is comparable to the rate reported in previous studies. ${ }^{26,27}$ In addition to OASIS, irritable bowel syndrome, high body mass index, and mode of delivery constitute factors associated with flatal incontinence. ${ }^{20,21}$ Overall, 5.5\% of women reported faecal incontinence; most of these women reported faecal incontinence to loose stool and mild symptoms only. Most obstetric anal sphincter injuries were not detected during clinical examination. Shortly after delivery, the presence of OASIS was not associated with symptoms of faecal or flatal incontinence, but a longer-term study is needed to confirm these findings. However, we previously found that only antenatal faecal incontinence symptoms increased the likelihood of faecal incontinence at 12 months after delivery $(\mathrm{OR}=6.1, \quad 95 \% \quad \mathrm{CI}=1.8-21.5, \quad \mathrm{P}=0.005)$, whereas maternal characteristics, mode of delivery, and the presence of OASIS did not. ${ }^{28}$ In longer-term follow-up (3-5 years after delivery), $2.1 \%$ and $5.9 \%$ of women who had one vaginal delivery reported faecal incontinence to solid and loose stool, respectively. ${ }^{29}$

To the best of our knowledge, there have been no randomised controlled trials regarding the optimal timing for the use of endoanal US to assess OASIS after vaginal delivery. One randomised controlled trial has been conducted to compare clinical examination alone (control group) and clinical examination with additional endoanal US immediately after delivery (intervention group)..$^{30,31}$ The results of that study showed that US performed immediately after delivery-before repair-might detect more cases of OASIS: $5.6 \%$ of women were found to have full-thickness OASIS that was not recognised during clinical examination alone. ${ }^{31}$ However, the study also showed that five of 21 women underwent unnecessary intervention, as the sonographic defect could not be clinically located, despite surgical exploration. ${ }^{31}$ Therefore, the use of endoanal US immediately after delivery and before repair was not recommended.

Women with OASIS should undergo followup after delivery to assess symptoms of faecal incontinence. Currently, there is no consensus regarding the optimal mode of delivery for these women in subsequent pregnancies. Scheer et $\mathrm{al}^{32}$ and Karmarkar et $\mathrm{al}^{33}$ assessed women who had OASIS in subsequent pregnancies using a questionnaire, 
endoanal US, and manometry. Vaginal delivery was recommended for asymptomatic women with normal findings. Women were reassessed after subsequent deliveries. There were no statistically significant differences in anal manometry findings, anal symptoms, or quality of life following subsequent vaginal delivery or caesarean section. ${ }^{32,33}$ In the study by Scheer et al, ${ }^{32}$ new OASIS occurred in only one woman after a vaginal delivery. Therefore, decisions regarding the mode of delivery for subsequent pregnancies after OASIS should be based on clinical symptoms, anal manometry, and endoanal US. This would help to preserve anal sphincter function and avoid unnecessary caesarean sections. Currently, the value of the above assessments is limited in Hong Kong. The significance of an incidental finding of occult anal sphincter defect remains uncertain.

\section{Conclusion}

The prevalence of OASIS determined by endoanal US was higher than the rate determined by clinical practice. This may indicate that additional training for midwives and doctors may be required to improve the detection of OASIS. At 6 to 12 months after delivery, OASIS was not associated with symptoms of faecal or flatal incontinence, but a longer-term study is needed to confirm these findings.

\section{Author contributions}

All authors had full access to the data, contributed to the study, approved the final version for publication, and take responsibility for its accuracy and integrity.

Concept or design of the study: RYK Cheung, SSC Chan. Acquisition of data: OYK Wan, RYK Cheung, LL Lee, SSC Chan.

Analysis or interpretation of data: SPK Kwok, SSC Chan.

Drafting of the article: All authors.

Critical revision for important intellectual content: SPK Kwok, OYK Wan, RYK Cheung, SSC Chan.

\section{Declaration}

The results from this research have been presented, in part, at the following conferences:

1. Wan OYK, Cheung RYK, Chan SSC. 6th Annual Meeting of the Asia-Pacific Urogynecology Association and 13th Japanese Society of Pelvic Organ Prolapse Surgery Joint Conference-Young Doctors Session. Okinawa, Japan, 22-24 March 2019 (oral abstract presentation).

2. Wan OYK, Kwok SPK, Cheung RYK, Chan SSC. Hospital Authority Convention 2019, Hong Kong, 14-15 May 2019 (e-poster presentation).

3. Kwok SPK, Wan OYK, Cheung RYK, Lee LL, Chung JPW, Chan SSC. Obstetrical and Gynaecological Society of Hong Kong Annual Scientific Meeting 2019, Hong Kong, 1-2 June 2019 (oral presentation).

\section{Conflicts of interest}

As an editor of the journal, JPW Chung was not involved in the peer review process. Other authors have disclosed no conflicts of interest.

\section{Funding/support}

This research received no specific grant from any funding agency in the public, commercial, or not-for-profit sectors.

\section{Ethics approval}

Ethics approval was obtained from local institute, The Joint Chinese University of Hong Kong-New Territories East Cluster Clinical Research Ethics Committee (Ref CRE2013.332). Written informed consent was obtained from all participants.

\section{References}

1. Fenner DE, Genberg B, Brahma P, Marek L, DeLancey JO. Fecal and urinary incontinence after vaginal delivery with anal sphincter disruption in an obstetrics unit in the United States. Am J Obstet Gynecol 2003;189:1543-50.

2. Thiagamoorthy G, Johnson A, Thakar R, Sultan AH. National survey of perineal trauma and its subsequent management in the United Kingdom. Int Urogynecol J 2014;25:1621-7.

3. Baghestan E, Irgens LM, Børdahl PE, Rasmussen S. Trends in risk factors for obstetric anal sphincter injuries in Norway. Obstet Gynecol 2010;116:25-34.

4. Ekéus C, Nilsson E, Gottvall K. Increasing incidence of anal sphincter tears among primiparas in Sweden: a population-based register study. Acta Obstet Gynecol Scand 2008;87:564-73.

5. Hong Kong College of Obstetricians and Gynaecologists. Territory-wide audit in Obstetrics \& Gynaecology; 2009.

6. Bates LJ, Melon J, Turner R, Chan SS, Karantanis E. Prospective comparison of obstetric anal sphincter injury incidence between an Asian and Western hospital. Int Urogynecol J 2019;30:429-37.

7. Carroli G, Mignini L. Episiotomy for vaginal birth. Cochrane Database Syst Rev 2009;(1):CD000081.

8. Cheung RY, Shek KL, Chan SS, Chung TK, Dietz HP. Pelvic floor muscle biometry and pelvic organ mobility in East Asian and Caucasian nulliparae. Ultrasound Obstet Gynecol 2015;45:599-604.

9. Andrews V, Sultan AH, Thakar R, Jones PW. Occult anal sphincter injuries-myth or reality? BJOG 2006;113:195200.

10. Guzmán Rojas RA, Shek KL, Langer SM, Dietz HP. Prevalence of anal sphincter injury in primiparous women. Ultrasound Obstet Gynecol 2013;42:461-6.

11. Sultan AH, Kamm MA, Hudson CN, Thomas JM, Bartram CI. Anal-sphincter disruption during vaginal delivery. N Engl J Med 1993;329:1905-11.

12. Chan SS, Cheung RY, Yiu KW, Lee LL, Leung TY, Chung TK. Pelvic floor biometry during first singleton pregnancy and the relationship with symptoms of pelvic floor disorders: a prospective observational study. BJOG 2014;121:121-9.

13. Chan SS, Cheung RY, Yiu KW, Lee LL, Chung TK. Pelvic floor biometry in Chinese primiparous women 1 year after delivery: a prospective observational study. Ultrasound Obstet Gynecol 2014;43:466-74.

14. Chung MY, Wan OY, Cheung RY, Chung TK, Chan SS. Prevalence of levator ani muscle injury and healthrelated quality of life in primiparous Chinese women 
after instrumental delivery. Ultrasound Obstet Gynecol 2015;45:728-33.

15. von Elm E, Altman DG, Egger M, Pocock SJ, Gøtzsche PC, Vandenbroucke JP; STROBE Initiative. The Strengthening the Reporting of Observational Studies in Epidemiology (STROBE) statement: guidelines for reporting observational studies. J Clin Epidemiol 2008;61:344-9.

16. Sultan AH. Obstetric perineal injury and anal incontinence. Clinical Risk 1999;5:193-6.

17. Chan SS, Cheung RY, Yiu AK, et al. Chinese validation of Pelvic Floor Distress Inventory and Pelvic Floor Impact Questionnaire. Int Urogynecol J 2011;22:1305-12.

18. Roos AM, Thakar R, Sultan A. Outcome of primary repair of obstetric anal sphincter injuries (OASIS): does the grade of tear matter? Ultrasound Obstet Gynecol 2010;36:368 74.

19. de Leeuw JW, Struijk PC, Vierhout ME, Wallenburg HC Risk factors for third degree perineal ruptures during delivery. BJOG 2001;108:383-7.

20. Aukee P, Sundström H, Kairaluoma MV. The role of mediolateral episiotomy during labour: analysis of risk factors for obstetric anal sphincter tears. Acta Obstet Gynecol Scand 2006;85:856-60.

21. Ramalingam K, Monga AK. Outcomes and follow-up after obstetric anal sphincter injuries. Int Urogynecol J 2013;24:1495-500.

22. Hauck YL, Lewis L, Nathan EA, White C, Doherty DA Risk factors for severe perineal trauma during vaginal childbirth: a Western Australian retrospective cohort study. Women Birth 2015;28:16-20.

23. Grobman WA, Bailit JL, Rice MM, et al. Racial and ethnic disparities in maternal morbidity and obstetric care. Obstet Gynecol 2015;125:1460-7.

24. Davies-Tuck M, Biro MA, Mockler J, Stewart L, Wallace
EM, East C. Maternal Asian ethnicity and the risk of anal sphincter injury. Acta Obstet Gynecol Scand 2015;94:30815

25. Stedenfeldt M, Øian P, Gissler M, Blix E, Pirhonen J. Risk factors for obstetric anal sphincter injury after a successful multicentre interventional programme. BJOG 2014;121:83-91.

26. Boreham MK, Richter HE, Kenton KS, et al. Anal incontinence in women presenting for gynecologic care: prevalence, risk factors, and impact upon quality of life. Am J Obstet Gynecol 2005;192:1637-42.

27. Melville JL, Fan MY, Newton K, Fenner D. Fecal incontinence in US women: a population-based study. Am J Obstet Gynecol 2005;193:2071-6.

28. Chan SS, Cheung RY, Yiu KW, Lee LL, Chung TK. Prevalence of urinary and fecal incontinence in Chinese women during and after first pregnancy. Int Urogynecol J 2013;24:1473-9.

29. Ng K, Cheung RY, Lee LL, Chung TK, Chan SS. An observational follow-up study on pelvic floor disorders to 3-5 years after delivery. Int Urogynecol J 2017;28:1393-9.

30. Walsh KA, Grivell RM. Use of endoanal ultrasound for reducing the risk of complications related to anal sphincter injury after vaginal birth. Cochrane Database Syst Rev 2015;(10):CD010826.

31. Faltin DL, Boulvain M, Floris LA, Irion O. Diagnosis of anal sphincter tears to prevent fecal incontinence: a randomized controlled trial. Obstet Gynecol 2005;106:6-13.

32. ScheerI, ThakarR,Sultan AH.Modeofdeliveryafterprevious obstetric anal sphincter injuries (OASIS) - a reappraisal? Int Urogynecol J Pelvic Floor Dysfunct 2009;20:1095-101.

33. Karmarkar R, Bhide A, Digesu A, Khullar V, Fernando R. Mode of delivery after obstetric anal sphincter injury. Eur J Obstet Gynecol Reprod Biol 2015;194:7-10. 